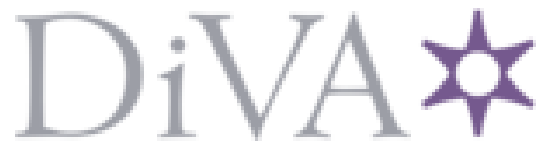

http://www.diva-portal.org

This is the published version of a paper published in Archives of Physical Medicine and Rehabilitation.

Citation for the original published paper (version of record):

Karlsson, Å., Lindelöf, N., Olofsson, B., Berggren, M., Gustafson, Y. et al. (2020)

Effects of Geriatric Interdisciplinary Home Rehabilitation on Independence in

Activities of Daily Living in Older People With Hip Fracture: A Randomized Controlled

Trial

Archives of Physical Medicine and Rehabilitation, 101(4): 571-578

https://doi.org/10.1016/j.apmr.2019.12.007

Access to the published version may require subscription.

N.B. When citing this work, cite the original published paper.

Permanent link to this version:

http://urn.kb.se/resolve?urn=urn:nbn:se:umu:diva-173439 


\title{
Effects of Geriatric Interdisciplinary Home Rehabilitation on Independence in Activities of Daily Living in Older People With Hip Fracture: A Randomized Controlled Trial
}

\author{
Åsa Karlsson, PT, MSc, ${ }^{a, b}$ Nina Lindelöf, PT, PhD, ${ }^{a, b}$ Birgitta Olofsson, RN, PhD, ${ }^{c, d}$ \\ Monica Berggren, MD, PhD, ${ }^{a}$ Yngve Gustafson, MD, PhD, ${ }^{a}$ Peter Nordström, MD, PhD, \\ Michael Stenvall, PT, PhD
}

From the ${ }^{a}$ Department of Community Medicine and Rehabilitation, Geriatric Medicine, Umea University, Umea:; ${ }^{b}$ Department of Community Medicine and Rehabilitation, Physiotherapy, Umea University, Umeå; ${ }^{c}$ Department of Nursing, Umea University, Umea; and the ${ }^{d}$ Department of Surgical and Perioperative Science, Orthopedics, Umea University, Umeå, Sweden.

\footnotetext{
Abstract

Objective: To evaluate the effects of early discharge followed by geriatric interdisciplinary home rehabilitation for older people with hip fracture on independence in activities of daily living (ADL) compared with inhospital geriatric care according to a multifactorial rehabilitation program. Design: Planned analysis of a randomized controlled trial with 3- and 12-month follow-ups.

Setting: Geriatric ward, ordinary housing, and residential care facilities.

Participants: Of 466 people screened for eligibility, participants $(\mathrm{N}=205)$ with acute hip fracture, aged 70 years or older, including those with cognitive impairment and those living in residential care facilities, were randomized to intervention or control groups.

Intervention: Individually designed interdisciplinary home rehabilitation for a maximum of 10 weeks. The intervention aimed at early hospital discharge and focused on prevention of falls, independence in daily activities, and walking ability indoors and outdoors.

Main Outcome Measures: Independence in ADL was measured using the Barthel ADL Index, and the ADL Staircase including the Katz ADL Index during hospital stay (prefracture performance) and at the follow-up visits in the participants' homes.

Results: There were no significant differences in ADL performance between the groups, and they recovered their prefracture level of independence in personal and instrumental ADL comparably. At 12 months, 33 (41.3\%) in the intervention group vs 33 (41.8\%) in the control group $(P=.99)$ had regained or improved their prefracture ADL performance according to the Barthel ADL Index, and $27(37.0 \%)$ vs $36(48.6 \%)$ according to the ADL Staircase $(P=.207)$.

Conclusions: In older people with hip fracture, early discharge followed by geriatric interdisciplinary home rehabilitation resulted in a comparable recovery of independence in ADL at 3 and 12 months as inhospital geriatric care and rehabilitation.

Archives of Physical Medicine and Rehabilitation 2020;101:571-8

(C) 2020 by the American Congress of Rehabilitation Medicine. Published by Elsevier Inc. This is an open access article under the CC BY-NC-ND license (http://creativecommons.org/licenses/by-nc-nd/4.0/).
}

\footnotetext{
Presented to the World Confederation for Physical Therapy Congress, May 10-13, 2019, Geneva, Switzerland.

Supported by the University of Umeå and County Council of Västerbotten; the Swedish Dementia Foundation; the Erik and Anne-Marie Detlof Foundation; Strategic Research Area Health Care Science Umeå University; and the Kempe Foundation.

Clinical Trial Registration No.: 15738119.

Disclosures: none.

0003-9993/20/C 2020 by the American Congress of Rehabilitation Medicine. Published by Elsevier Inc. This is an open access article under the CC BYNC-ND license (http://creativecommons.org/licenses/by-nc-nd/4.0/).

https://doi.org/10.1016/j.apmr.2019.12.007
} 
Hip fracture is a serious event for the older individual with negative consequences on mobility and the ability to perform activities of daily living (ADL). ${ }^{1-3}$ In order to optimize recovery, the rehabilitation should include an orthogeriatric care model with an interdisciplinary team, using comprehensive geriatric assessment. ${ }^{4,5}$ Length of stay (LOS) in the hospital has been reduced over the recent decades, which has contributed to the establishment of home rehabilitation (HR) teams for continuation of the rehabilitation after discharge. ${ }^{6}$

The evidence for team-based rehabilitation after hip fracture in the home setting is still limited, but positive effects on ADL and mobility compared with usual inhospital care have been shown. ${ }^{5,7}$ Some studies have reported improved self-care performance, also called basic ADL or personal ADL (PADL), for the HR group compared to usual care, in the short-term ${ }^{8,9}$ and long-term perspective. ${ }^{10,11}$ Furthermore, a year-long comprehensive HR intervention improved both self-care and instrumental ADL (IADL) performance compared to usual care. ${ }^{12}$ In contrast, 2 other studies observed no significant effects on self-care or IADL with their HR interventions, ${ }^{13,14}$ although one of them, albeit multicomponent, was not team-based. ${ }^{14}$

The generalizability of the results in previous team-based HR interventions is of particular concern, since they did not include people with severe cognitive impairment or dementia, those with serious medical conditions, or those living in residential care facilities. These groups represent a large proportion of older people with hip fracture, and have an additionally higher risk of poor functional recovery than people who are cognitively intact, not seriously ill, and live in ordinary housing. ${ }^{15}$ We have included people with severe cognitive impairment and those living in residential care facilities in our previous papers evaluating the present geriatric interdisciplinary home rehabilitation intervention (GIHR) and showed that the postoperative hospital LOS could significantly be reduced with a median of 6 days. ${ }^{16}$ The GIHR group regained walking ability to the same extent as the control group with no significant differences in complications during the year after the fracture. ${ }^{16,17}$

The aim of this planned analysis was to evaluate the effects of GIHR on independence in ADL at 3 and 12 months in a representative sample of older people with hip fracture compared with inhospital geriatric care according to a multifactorial rehabilitation program.

\section{Methods}

\section{Study design and participants}

This study was part of a randomized controlled trial (RCT), conducted at the Geriatric Department of the University Hospital

\begin{tabular}{|l|}
\hline List of abbreviations: \\
ADL activities of daily living \\
CI confidence interval \\
GIHR geriatric interdisciplinary home rehabilitation \\
HR home rehabilitation \\
IADL instrumental activities of daily living \\
LOS length of stay \\
OR odds ratio \\
PADL personal activities of daily living \\
RCT randomized controlled trial \\
\hline
\end{tabular}

of Umeå in Sweden. Primary outcomes of the RCT were hospital LOS including readmissions, complications, depression, delirium, walking ability, and ADL performance. A detailed description of the RCT has been reported earlier, ${ }^{16,17}$ and ethical approval was obtained from the Regional Ethical Review Board in Umeå, Sweden 2008 (DNR 08-053M).

The inclusion criteria were acute hip fracture surgery (cervical or trochanteric fracture), age 70 years or older, and living in the municipality of Umeå in ordinary housing or in residential care facilities. People with cognitive impairment or dementia were included. Those with pathological fractures and those who fractured their hips in the hospital were excluded.

\section{Procedure}

The participants were consecutively randomized from May 2008 to June 2011 using sequentially numbered lots in opaque, sealed envelopes drawn by a ward nurse who was not involved in the study. The participants were randomized to inhospital geriatric care and rehabilitation with GIHR after discharge, or to inhospital geriatric care and rehabilitation. The randomization was stratified according to type of housing and type of fracture. Study information was given to the participants both orally and in writing; in the presence of cognitive impairment, the next of kin was also consulted. Two experienced and trained researchers, 1 registered nurse and 1 physiotherapist (blinded to group allocation), assessed the participants during their hospital stay and postoperatively at 3 and 12 months in their homes.

\section{Control group}

Inhospital care and rehabilitation in the geriatric ward was based on a multifactorial rehabilitation program, which has been scientifically evaluated ${ }^{18-20}$ and was implemented at the ward in 2000. In short, the program consists of interdisciplinary rehabilitation using comprehensive geriatric assessment with individual rehabilitation plans, participation of the whole staff in the patient's everyday activities, and a thorough discharge plan. An important part of the inhospital program was to detect, prevent, and treat postoperative complications. The occupational therapist and physiotherapist provided specific retraining in PADL, transfers, and walking. Participants who needed additional rehabilitation after discharge were referred to primary health care and, 3 months after the fracture, they could also receive rehabilitation at a geriatric outpatient rehabilitation unit. For participants living in residential care facilities, physiotherapists and occupational therapists in the facilities were contacted to communicate the need for continued rehabilitation after discharge.

\section{Intervention}

Participants randomized to the GIHR intervention were also treated according to the multifactorial rehabilitation program initially but with the aim of an early discharge and continuation of rehabilitation in their homes with support of the interdisciplinary team for a maximum of 10 weeks. Discharge was possible when the participants had no medical obstacles, could manage basic transfers, and had the care they required at home. The GIHR intervention has been previously described in detail. ${ }^{16,17}$ The team was comprised of a nurse, an occupational therapist, and 2 physiotherapists who visited the participants 
regularly. A geriatrician was medically responsible, and a social worker and a dietician could be consulted when necessary. The rehabilitation was individually tailored (ie, team actions, the length of the rehabilitation period) and the number of home visits varied for each participant according to their individual rehabilitation plan. The intervention was completed when the goals of the individual rehabilitation plan were achieved or, in some cases, when the team felt that the goals turned out to be unrealistic or not achievable. Median days of the intervention was 21 with an average of 14 home visits. ${ }^{16}$ The intervention included multifactorial actions in order to prevent falls, modifications of the home environment, specific training in PADL and IADL, and in the use of assistive devices. Further, walking exercises and progressive functional strength and balance training according to The High-Intensity Functional Exercise (HIFE) Program were included. ${ }^{21,22}$ The medical part focused on prevention, detection, and treatment of complications after discharge, evaluation of pain, and assessment of the participants' ability to handle their medicines safely. The participants' nutrition was also evaluated and all team members worked together to improve their nutritional status; in some cases, this was with support of the dietician. The GIHR team worked in close contact with the next of kin, home social services, or with the staff at the residential care facilities.

\section{Baseline assessments}

During hospital stay, the assessors interviewed the participant (and, in the presence of cognitive impairment, also the next of kin or a nurse in the residential care facility), about the participant's prefracture social situation, medical history, prescribed drugs, and walking ability. ${ }^{23}$ Cognition was evaluated using the Mini Mental State Examination, ${ }^{24}$ depressive disorders were assessed using the Geriatric Depression Scale, ${ }^{25}$ and delirium was assessed with the Organic Brain Syndrome Scale. ${ }^{26}$

\section{Main outcome measures}

ADL performance, the primary outcome evaluated in this study, was assessed using the Barthel ADL Index, ${ }^{27,28}$ and the ADL Staircase (which includes the Katz ADL Index). ${ }^{29,30}$ The assessors interviewed the participants regarding their independence in ADLs at baseline (prefracture performance) and at 3 and 12 months. If cognitive impairment was present, the next of kin or care staff were also consulted. The Barthel Index and the Katz Index both measure PADL including feeding, continence, transfer, toilet use, bathing, and dressing, and the former scale measures mobility as well. The Barthel Index ranges from 0-20, with the highest number indicating independence, and the Katz Index scores from A-G, with A indicating independence. In the ADL Staircase, the Katz Index is extended to also include 4 items that measure IADL (cooking, cleaning, shopping, and public transport). The ADL Staircase score ranges from $0-10$ with 0 indicating independence in all activities.

After study completion, medical data were registered according to a preset protocol by reading the participants' medical records and assessments; documentations were analyzed to determine if the participants fulfilled the criteria for dementia, delirium, and depressive disorders (Diagnostic and Statistical Manual of Mental Disorders, 4th edition).

\section{Statistics}

Sample size was calculated for 1 of the planned primary outcomes in the RCT - hospital LOS - and was based on the number of days patients with hip fracture spent in the hospital during a year in a previous study. ${ }^{18}$ Assuming a power of $80 \%$ and with a $24 \%$ reduction in hospital days, the total sample size was estimated to be 206 participants. Differences between the GIHR and control group were analyzed with the Student $t$ test for independent samples for normally distributed continuous variables, the Pearson chi-square test (with Yates continuity correction) or Fisher exact test for dichotomous data, and the Mann-Whitney $U$ test for ordinal data and data that were not normally distributed. Category $\mathrm{A}$ in the Katz ADL Index was considered as independence in PADL. A binary logistic regression method was used to analyze the odds ratio (OR) of independence in each item of the ADL Staircase according to group allocation. Spearman coefficients was used to test correlations between variables in the model. The first model was adjusted for age, sex, and prefracture status of the outcome variable and in the final model, significant differences between the groups at baseline (antidepressants, analgesics,

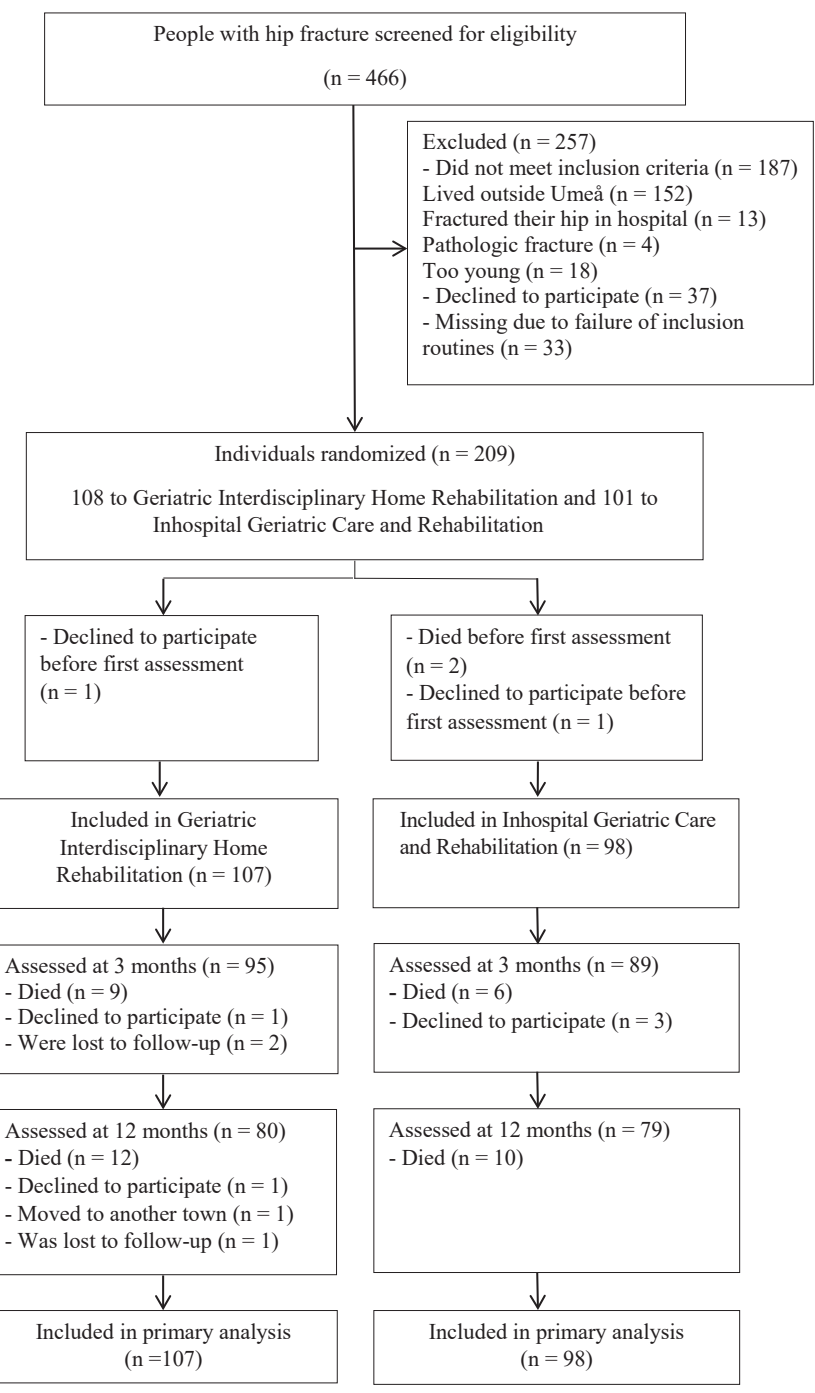

Fig 1 Flow chart showing the randomization and follow-up at 3 and 12 months. 
Table 1 Baseline characteristics

\begin{tabular}{|c|c|c|c|}
\hline Characteristics & Total $\mathrm{N}=205$ & GIHR $n=107$ & Control $n=98$ \\
\hline Age $(y)$, mean $\pm S D$ & $82.9 \pm 6.7$ & $83.2 \pm 7.0$ & $82.6 \pm 6.4$ \\
\hline Female sex, n (\%) & $147(71.7)$ & $79(73.8)$ & $68(69.4)$ \\
\hline Cervical fracture, $\mathrm{n}(\%)$ & $148(72.2)$ & $78(72.9)$ & $70(71.4)$ \\
\hline Trochanteric fracture, $\mathrm{n}(\%)$ & $57(27.8)$ & $29(27.1)$ & $28(28.6)$ \\
\hline Living in ordinary home, $\mathrm{n}(\%)$ & $142(69.3)$ & $71(66.4)$ & $71(72.4)$ \\
\hline Living in residential care facilities, $\mathrm{n}(\%)$ & $63(30.7)$ & $36(33.6)$ & $27(27.6)$ \\
\hline Living alone, n (\%) & $147(71.7)$ & $78(72.9)$ & $69(70.4)$ \\
\hline \multicolumn{4}{|l|}{ Diagnoses and medical conditions } \\
\hline Previous hip fracture, $\mathrm{n}(\%)$ & $35(17.1)$ & $20(18.7)$ & $15(15.3)$ \\
\hline Impaired vision, ${ }^{*} n(\%),(n=191)$ & $31(16.2)$ & $17(17.0)$ & $14(15.4)$ \\
\hline Dementia, n (\%) & $103(50.2)$ & $57(53.3)$ & $46(46.9)$ \\
\hline Depressive disorders, $n(\%),(n=203)$ & $77(37.9)$ & $47(44.3)$ & $30(30.9)$ \\
\hline Stroke, n (\%) & $45(22.0)$ & $21(19.6)$ & $24(24.5)$ \\
\hline Mini Mental State Examination (0-30), median (IQR), $(n=199)$ & $19(11-25)$ & $18(11-25)$ & $19(11-25)$ \\
\hline Delirium during hospitalization, $\mathrm{n}(\%)$ & $153(74.6)$ & $84(78.5)$ & $69(70.4)$ \\
\hline Number of comorbidities $\geq 3, \mathrm{n}(\%)$ & $120(58.5)$ & $66(61.7)$ & $54(55.1)$ \\
\hline \multicolumn{4}{|l|}{ Operative methods } \\
\hline Internal fixation, $\mathrm{n}(\%)$ & $48(23.4)$ & $26(24.3)$ & $22(22.4)$ \\
\hline Hemiarthroplasty, n (\%) & $86(42.0)$ & $43(40.2)$ & $43(43.9)$ \\
\hline Sliding hip screw, n (\%) & $41(20.0)$ & $23(21.5)$ & $18(18.4)$ \\
\hline Other methods, $\mathrm{n}(\%)$ & $30(14.6)$ & $15(14.0)$ & $15(15.3)$ \\
\hline \multicolumn{4}{|l|}{ Functional performance before fracture } \\
\hline Independent in $\mathrm{PADL}^{\dagger} \mathrm{n}(\%)$ & $92(44.9)$ & $45(42.1)$ & $47(48.0)$ \\
\hline Independent in both $\mathrm{P}$ and $\mathrm{IADL},{ }^{\ddagger} \mathrm{n}(\%)$ & $35(17.1)$ & $22(20.6)$ & $13(13.3)$ \\
\hline Barthel ADL Index (0-20), median (IQR) & $18(13-20)$ & $18(13-20)$ & $18(13-20)$ \\
\hline ADL Staircase $(0-10), \|$ median (IQR), $(n=198)$ & $5(1-7)$ & $5(1-7)$ & $4(1-7)$ \\
\hline Walking independently indoors, $\mathrm{n}(\%)$ & $180(87.8)$ & $95(88.8)$ & $85(86.7)$ \\
\hline Walking independently outdoors, $\mathrm{n}(\%)$ & $141(68.8)$ & $70(65.4)$ & $71(72.4)$ \\
\hline \multicolumn{4}{|l|}{ Medications at discharge } \\
\hline Number of prescribed drugs, mean $\pm S D$ & $8.5 \pm 3.1$ & $8.8 \pm 3.0$ & $8.3 \pm 3.3$ \\
\hline Analgesics (not ASA), n (\%) & $177(86.3)$ & $87(81.3)$ & $90(91.8)$ \\
\hline Antidepressants, n (\%) & $75(36.6)$ & $49(45.8)$ & $26(26.5)$ \\
\hline Benzodiazepines, n (\%) & $27(13.2)$ & $15(14.0)$ & $12(12.2)$ \\
\hline Beta blockers, n (\%) & $76(37.1)$ & $42(39.3)$ & $34(34.7)$ \\
\hline Diuretics, $\mathrm{n}(\%)$ & $70(34.1)$ & $36(33.6)$ & $34(34.7)$ \\
\hline Neuroleptics, n (\%) & $23(11.2)$ & $10(9.3)$ & $13(13.3)$ \\
\hline Parkinson medications, n (\%) & $11(5.4)$ & $10(9.3)$ & $1(1.0)$ \\
\hline $\begin{array}{l}\text { NOTE. Numbers reported after covariates indicate number of measureme } \\
\text { Abbreviations: ASA, acetylsalicylic acid; IQR, interquartile range. } \\
\text { * Indicates not able to read 5-mm capital letters at reading distance, } \\
\dagger \text { Category A according to Katz ADL Index. } \\
\ddagger \text { According to ADL Staircase. } \\
\S \text { Higher score indicates better status. } \\
\text { " Lower score indicates better status. }\end{array}$ & $\begin{array}{l}\text { able when values } \\
\text { without glasses. }\end{array}$ & sing. & \\
\hline
\end{tabular}

Parkinson medications) were also added. SPSS version $24^{\text {a }}$ was used for statistical calculations, and all analyses were based on the intention-to-treat principle using available data from all participants, according to their original allocation and regardless of level of attendance. All tests were 2-tailed, and the significance level was set at $P \leq .05$.

\section{Results}

Of 466 people screened for eligibility, 205 participants were included in the study (fig 1). The group of people who declined to participate $(n=37)$ or were missed because the inclusion routines failed $(n=33)$ did not differ in age or sex from those included in the study (see fig 1). The use of antidepressants, analgesics, and Parkinson medications differed between the groups, but no other significant between-group differences were seen in baseline characteristics (table 1).

There were no significant differences between the groups in median total score of the Barthel ADL Index, the Katz ADL Index, or the ADL Staircase at 3 and 12 months (table 2). Similarly, there was no difference between the groups regarding independence in PADL at the 2 follow-up visits. At 3 months, 28 $(29.5 \%)$ in the GIHR group and $26(29.2 \%)$ in the control group 
Table 2 Median score of the Barthel ADL Index, Katz ADL Index, and ADL Staircase at the 3- and 12-month follow-up

\begin{tabular}{llll}
\hline Outcome & $\begin{array}{l}\text { GIHR } \\
\text { Median (IQR) }\end{array}$ & $\begin{array}{l}\text { Control } \\
\text { Median (IQR) }\end{array}$ & $P$ Value \\
\hline Barthel ADL Index* & & & \\
3 mo & $15(8-20)$ & $16(11-19)$ & .888 \\
12 mo & $17(8-20)$ & $17(9-19)$ & .828 \\
Katz ADL Index & & & \\
3 mo $(n=179)$ & $4(2-6)$ & $3(1-6)$ & .362 \\
12 mo $(n=151)$ & $2(1-6)$ & $2(1-6)$ & .668 \\
ADL Staircase & & & \\
3 mo $(n=176)$ & $7(4-9)$ & $6(4-9)$ & .435 \\
12 mo ( $n=150)$ & $5(2-9)$ & $5(3-9)$ & .687 \\
\hline NOTE. Numbers reported after covariates indicate number of measure- \\
ments available when values were missing. \\
Abbreviation: IQR, interquartile range. \\
* Higher score indicates better status. \\
$\quad+$ Lower score indicates better status.
\end{tabular}

$(P=.99)$ were independent in PADL with some improvement at 12 months: $31(38.8 \%)$ vs $29(36.7 \%)$ for the GIHR and control group, respectively $(P=.919)$.

Table 3 shows proportions of independence in the items of the ADL Staircase, and ORs of being treated in the GIHR group. In the first binary regression model, which was adjusted for age, sex, and prefracture status of the outcome variable, independence in cooking at 3 months was associated with allocation to the control group (OR, 0.37; 95\% CI, 0.1-0.95). After adjusting for baseline differences in the final model, that item did not remain significant; however, participants in the GIHR group were more likely to be independent in bathing at 3 months (OR, 3.39; 95\% CI, 1.0910.59). No other significant differences between the groups were found.

Recovery of at least the same ADL performance as before the fracture was analyzed for the main outcome measures and revealed no differences between the groups at 3 and 12 months (table 4). Similarly, there were no between-group differences among those who recovered the ability to perform PADL independently. At 3 months, 53 out of 90 participants who were independent in PADL before the fracture had regained that ability: 28 in the GIHR group vs 25 in the control group $(P=.496)$. At 12 months, the numbers were 57 out of 84 with 29 in the GIHR group vs 28 in the control group $(P=.340)$.

\section{Discussion}

This study showed that the participants in the GIHR group had comparable PADL and IADL performance at 3 and 12 months to those receiving inhospital geriatric care, and they also regained their prefracture level of independence in ADL to the same extent. At 12 months, about $40 \%$ in the present study had recovered their prefracture ability in ADL according to the Barthel ADL Index and the ADL Staircase. A previous review of cohort studies reported that $40 \%-70 \%$ regained their level of independence in basic ADL within 2 years after the fracture, and in an RCT evaluating an HR intervention, $74 \%$ of the participants in the HR group had recovered prefracture ability in self-care ADL at 12 months, but no between-group differences were found. ${ }^{13}$ The authors discuss that exclusion of cognitively impaired persons may have had a positive effect on their results. In the present study, we included the most vulnerable subgroups: people with dementia and people living in residential care facilities. Before the fracture, $45 \%$ of the participants were independent in PADL, and at baseline, 50\% were diagnosed with dementia, which is a progressive disease and the leading cause of dependence in ADL. ${ }^{31}$ Despite that, a high number of the participants were independent in PADL at 12 months. These results have some important implications. It has been reported that short hospital LOS after hip fracture was associated with increased risk of complications and death. ${ }^{32,33}$ The results of the present study are therefore of interest, since the initial LOS in hospital for the GIHR group could be reduced by 6 days ${ }^{16}$ with a recovery in ADL comparable to those receiving inhospital geriatric care. Furthermore, our findings suggest that even the most vulnerable people with hip fracture have the capacity to recover with appropriate rehabilitation.

The GIHR intervention was limited to 10 weeks. Since exercise interventions for older people with dementia should last for some months, ${ }^{34}$ a more comprehensive HR intervention (over a longer period of time) might have been more beneficial for improvements in ADL when considering the high proportion of people with cognitive impairment. Moreover, the intervention was not tailored specifically toward people with dementia who may perhaps need more supervision, such as 24-hour care, to improve in ADL. However, the intervention did include supervised and task-specific training in the daily activities that were important to the individuals. Next of kin, staff in home social services, or staff at the facilities were also informed about how to support the participants in their daily activities, but there might have been a gap between the participants' functional capacity and what was practiced in everyday life, depending on the caregiver's motivation, knowledge, and working conditions.

Strengths of the study include that data were collected by blinded assessors, and the follow-up assessments were performed in the participants' homes, which probably reduced the number of dropouts. Furthermore, the GIHR intervention was compared with best practice: this is a multifactorial inhospital rehabilitation program that has been shown to reduce postoperative complications, improve mobility, ADL, and shorten hospital LOS. ${ }^{18-20}$ To our knowledge, the present study is the first RCT with a team-based HR intervention that has included a representative sample of people with hip fracture, altogether increasing external validity with respect to vulnerable older people with hip fracture.

\section{Study limitations}

Some study limitations should be considered. The power calculation was not based on ADL, but on another primary outcome of the RCT: the hospital LOS. Moreover, the study was not designed to be an equivalence trial, so the lack of difference between the groups in ADL may be due to insufficient power to show equivalence. Of all the items in the ADL Staircase, only bathing at 3 months was significantly associated with allocation to the GIHR group, and this result should be interpreted with caution. Further, we did not make any corrections for multiple comparisons, but the regression analyses were adjusted for between-group differences at baseline.

Data on ADL were collected through an interview and when the participant could not answer; the next of kin, a nurse, or a nurse's aide was asked to report on the participant's ADL 
Table 3 Independence in the items of the ADL Staircase before fracture and at the 3-and 12-month follow-up, and odds ratios of being treated in the GIHR group

\begin{tabular}{|c|c|c|c|c|}
\hline Item & GIHR $n=107$ & Control $n=98$ & Adjusted $\mathrm{OR}^{*}$ & $95 \% \mathrm{CI}$ \\
\hline \multicolumn{5}{|l|}{ Independent in dressing, $\mathrm{n}(\%)$} \\
\hline Before fracture, $(n=204)$ & $66(62.3)$ & $61(62.2)$ & & \\
\hline At 3-mo follow-up, $(n=182)$ & $38(40.4)$ & $43(48.3)$ & 1.35 & $0.54-3.35$ \\
\hline At 12 -mo follow-up, $(n=158)$ & $43(53.8)$ & $45(57.0)$ & 1.96 & $0.71-5.43$ \\
\hline \multicolumn{5}{|l|}{ Independent in bathing, $\mathrm{n}(\%)$} \\
\hline Before fracture, $(n=204)$ & $46(43.4)$ & $49(50.0)$ & & \\
\hline At 3-mo follow-up, $(n=181)$ & $28(30.1)$ & $26(29.2)$ & $3.39^{\dagger}$ & $1.09-10.59$ \\
\hline At 12-mo follow-up, $(n=158)$ & $31(38.8)$ & $29(36.7)$ & 2.87 & $0.98-8.43$ \\
\hline \multicolumn{5}{|l|}{ Independent in toilet use, $\mathrm{n}(\%)$} \\
\hline Before fracture & $84(78.5)$ & $71(72.4)$ & & \\
\hline At 3-mo follow-up, $(n=183)$ & $54(57.4)$ & $52(58.4)$ & 1.08 & $0.44-2.66$ \\
\hline At 12 -mo follow-up & $52(65.0)$ & $53(67.1)$ & 1.17 & $0.41-3.30$ \\
\hline \multicolumn{5}{|l|}{ Independent in transfer, $\mathrm{n}(\%)$} \\
\hline Before fracture & $94(87.9)$ & $84(85.7)$ & & \\
\hline At 3-mo follow-up & $59(62.1)$ & $59(66.3)$ & 1.06 & $0.47-2.39$ \\
\hline At 12 -mo follow-up & $53(66.3)$ & $58(73.4)$ & 0.72 & $0.28-1.87$ \\
\hline \multicolumn{5}{|l|}{ Independent in continence, $\mathrm{n}(\%)$} \\
\hline Before fracture & $74(70.5)$ & $67(68.4)$ & & \\
\hline At 3-mo follow-up, $(n=180)$ & $56(60.2)$ & $60(67.4)$ & 0.96 & $0.42-2.21$ \\
\hline At 12 -mo follow-up, $(n=156)$ & $49(62.0)$ & $55(69.6)$ & 1.05 & $0.40-2.77$ \\
\hline \multicolumn{5}{|l|}{ Independent in feeding, $\mathrm{n}(\%)$} \\
\hline Before fracture & $97(90.7)$ & $84(85.7)$ & & \\
\hline At 3-mo follow-up & $81(85.3)$ & $78(87.6)$ & 1.00 & $0.35-2.84$ \\
\hline At 12 -mo follow-up & $63(78.8)$ & $68(86.1)$ & 0.46 & $0.15-1.35$ \\
\hline \multicolumn{5}{|l|}{ Independent in cooking, $\mathrm{n}(\%)$} \\
\hline Before fracture & $39(36.4)$ & $36(36.7)$ & & \\
\hline At 3-mo follow-up, $(n=183)$ & $20(21.3)$ & $27(30.3)$ & 0.47 & $0.17-1.31$ \\
\hline At 12 -mo follow-up, $(n=158)$ & $22(27.8)$ & $25(31.6)$ & 1.23 & $0.45-3.36$ \\
\hline \multicolumn{5}{|l|}{ Independent in cleaning, $\mathrm{n}(\%)$} \\
\hline Before fracture & $29(27.1)$ & $20(20.4)$ & & \\
\hline At 3-mo follow-up, $(n=181)$ & $13(14.0)$ & $8(9.1)$ & 1.61 & $0.49-5.30$ \\
\hline At 12-mo follow-up, $(n=158)$ & $17(21.3)$ & $11(14.1)$ & 2.51 & $0.87-7.23$ \\
\hline \multicolumn{5}{|l|}{ Independent in shopping, $\mathrm{n}(\%)$} \\
\hline Before fracture & $29(27.1)$ & $28(28.6)$ & & \\
\hline At 3-mo follow-up, $(n=183)$ & $10(10.6)$ & $7(7.9)$ & 1.85 & $0.54-6.36$ \\
\hline At 12-mo follow-up, $(n=158)$ & $14(17.5)$ & $15(19.2)$ & 1.27 & $0.46-3.55$ \\
\hline \multicolumn{5}{|c|}{ Independent in public transport, $\mathrm{n}(\%)$} \\
\hline Before fracture, $(n=200)$ & $35(33.7)$ & $32(33.3)$ & & \\
\hline At 3-mo follow-up, $(n=180)$ & $16(17.4)$ & $10(11.4)$ & 2.10 & $0.70-6.35$ \\
\hline At 12 -mo follow-up, $(n=149)$ & $12(16.2)$ & $10(13.2)$ & 1.40 & $0.44-4.49$ \\
\hline
\end{tabular}

performance. This method was considered the best available since baseline data on ADL concerned the participants' prefracture performance and made it possible to also include people with severe cognitive impairment. However, this may have influenced the results since proxy respondents tend to report more disability. ${ }^{35}$ There is also a risk of recall bias in the baseline data on ADL since the data were based on interviews where the participants were asked about their prefracture functional status. Moreover, the outcome measures used have a limited ability to measure small changes and were perhaps not sensitive enough to detect improvements in ADL. ${ }^{36}$
There was a tendency that participants in the GIHR group had a worse health status at baseline. The proportion of depression was higher, more participants had Parkinson disease, and, as we have previously reported, more participants in the GIHR group had an additional fracture after discharge. ${ }^{17}$ This may have had a negative effect on independence in ADL. Moreover, 7 participants who were randomized to the GIHR group did not get the intervention; 6 participants were judged not to need HR due to long hospital stays with continued inhospital rehabilitation; and 1 participant was missed. However, according to the intention-to-treat principle, they are included in the analyses. ${ }^{16}$ In both groups, there was a 
Table 4 Recovery of prefracture ADL performance for the groups at the 3- and 12-month follow-up

\begin{tabular}{llll}
\hline Outcome & GIHR n (\%) & Control n (\%) & $P$ Value \\
\hline Barthel ADL Index & & & \\
$\quad 3$ mo & $38(40.0)$ & $38(42.7)$ & .825 \\
$12 \mathrm{mo}$ & $33(41.3)$ & $33(41.8)$ & .99 \\
Katz ADL Index & & & \\
$\quad 3 \mathrm{mo},(n=175)$ & $43(47.3)$ & $42(50.0)$ & .832 \\
$\quad 12 \mathrm{mo},(n=146)$ & $39(52.7)$ & $46(63.9)$ & .229 \\
ADL Staircase & & & \\
3 mo, $(n=171)$ & $27(30.7)$ & $33(39.8)$ & .279 \\
12 mo, $(n=147)$ & $27(37.0)$ & $36(48.6)$ & .207 \\
\hline
\end{tabular}

NOTE. Recovery was defined as a score at least as high or at the same level as before the fracture. Numbers reported after covariates indicate number of measurements available when values were missing.

selection bias for the group of people with trochanteric fractures. This is because only those who needed a longer rehabilitation period could be included in the study, which may have had a negative effect on ADL and may have altered the external validity. Finally, we do not know to what extent the participants in the control group, who were living in residential care facilities, received rehabilitation after discharge.

\section{Conclusions}

In older people with hip fracture, early discharge followed by a GIHR intervention resulted in a recovery of independence in ADL at 3 and 12 months that was comparable to inhospital geriatric care according to a multifactorial rehabilitation program.

Future research is needed to further evaluate the effectiveness of team-based HR for the whole group of people with hip fracture and to explore the participants' experiences of participating in a geriatric interdisciplinary HR intervention.

\section{Supplier}

a. SPSS version 24; IBM Corp.

\section{Keywords}

Activities of daily living; Geriatrics; Hip fractures; Patient care team; Rehabilitation

\section{Corresponding author}

Åsa Karlsson, PT, MSc, Department of Community Medicine and Rehabilitation, Geriatric Medicine, Umeå University, SE- 90187 Umeå, Sweden. E-mail address: asa.karlsson@umu.se.

\section{Acknowledgments}

We thank the staff at the geriatric ward and the home rehabilitation team at the University Hospital of Umeå for their participation in the clinical trial. We also thank Helen Abrahamsson, OT,
Eva Elinge, OT, Med.Lic, and Anita Persson, RN, for their efforts in the development and implementation of the study.

\section{References}

1. Dyer SM, Crotty M, Fairhall N, et al. A critical review of the longterm disability outcomes following hip fracture. BMC Geriatr 2016; 16:158.

2. Alarcon T, Gonzalez-Montalvo JI, Gotor P, Madero R, Otero A. Activities of daily living after hip fracture: profile and rate of recovery during 2 years of follow-up. Osteoporos Int 2011;22:1609-13.

3. Stenvall M, Elinge E, von Heideken Wågert P, Lundström M, Gustafson Y, Nyberg L. Having had a hip fracture-association with dependency among the oldest old. Age Ageing 2005;34:294-7.

4. Tarazona-Santabalbina FJ, Belenguer-Varea A, Rovira E, CuestaPeredo D. Orthogeriatric care: improving patient outcomes. Clin Interv Aging 2016;11:843-56.

5. Nordström P, Thorngren KG, Hommel A, Ziden L, Anttila S. Effects of geriatric team rehabilitation after hip fracture: meta-analysis of randomized controlled trials. J Am Med Dir Assoc 2018;19:840-5.

6. Swedish Council on Health Technology Assessment (SBU). Advanced home health care and home rehabilitation. Stockholm, Sweden: SBU; 1999.

7. Donohue K, Hoevenaars R, McEachern J, Zeman E, Mehta S. Homebased multidisciplinary rehabilitation following hip fracture surgery: what is the evidence? Rehabil Res Pract 2013;2013:875968.

8. Crotty M, Whitehead CH, Gray S, Finucane PM. Early discharge and home rehabilitation after hip fracture achieves functional improvements: a randomized controlled trial. Clin Rehabil 2002;16:406-13.

9. Ziden L, Frändin K, Kreuter M. Home rehabilitation after hip fracture. A randomized controlled study on balance confidence, physical function and everyday activities. Clin Rehabil 2008;22:1019-33.

10. Zidén L, Kreuter M, Frändin K. Long-term effects of home rehabilitation after hip fracture - 1-year follow-up of functioning, balance confidence, and health-related quality of life in elderly people. Disabil Rehabil 2010;32:18-32.

11. Shyu YI, Liang J, Wu CC, et al. Two-year effects of interdisciplinary intervention for hip fracture in older Taiwanese. J Am Geriatr Soc 2010;58:1081-9.

12. Shyu YI, Liang J, Tseng MY, et al. Enhanced interdisciplinary care improves self-care ability and decreases emergency department visits for older Taiwanese patients over 2 years after hip-fracture surgery: a randomised controlled trial. Int J Nurs Stud 2016;56:54-62.

13. Tinetti ME, Baker DI, Gottschalk M, et al. Home-based multicomponent rehabilitation program for older persons after hip fracture: a randomized trial. Arch Phys Med Rehabil 1999;80:916-22.

14. Edgren J, Salpakoski A, Sihvonen SE, et al. Effects of a home-based physical rehabilitation program on physical disability after hip fracture: a randomized controlled trial. J Am Med Dir Assoc 2015;16: 350e1-7.

15. Beaupre LA, Binder EF, Cameron ID, et al. Maximising functional recovery following hip fracture in frail seniors. Best Pract Res Clin Rheumatol 2013;27:771-88.

16. Karlsson Å, Berggren M, Gustafson Y, Olofsson B, Lindelöf N, Stenvall M. Effects of geriatric interdisciplinary home rehabilitation on walking ability and length of hospital stay after hip fracture: a randomized controlled trial. J Am Med Dir Assoc 2016;17:464-e9-15.

17. Berggren M, Karlsson $\AA$, Lindelöf N, et al. Effects of geriatric interdisciplinary home rehabilitation on complications and readmissions after hip fracture: a randomized controlled trial. Clin Rehabil 2019;33:64-73.

18. Stenvall M, Olofsson B, Lundström M, et al. A multidisciplinary, multifactorial intervention program reduces postoperative falls and injuries after femoral neck fracture. Osteoporos Int 2007;18:167-75.

19. Lundström M, Olofsson B, Stenvall M, et al. Postoperative delirium in old patients with femoral neck fracture: a randomized intervention study. Aging Clin Exp Res 2007;19:178-86. 
20. Stenvall M, Olofsson B, Nyberg L, Lundström M, Gustafson Y. Improved performance in activities of daily living and mobility after a multidisciplinary postoperative rehabilitation in older people with femoral neck fracture: a randomized controlled trial with 1-year follow-up. J Rehabil Med 2007;39:232-8.

21. Littbrand H, Rosendahl E, Lindelöf N, Lundin-Olsson L, Gustafson Y, Nyberg L. A high-intensity functional weight-bearing exercise program for older people dependent in activities of daily living and living in residential care facilities: evaluation of the applicability with focus on cognitive function. Phys Ther 2006;86:489-98.

22. Littbrand H, Lindelöf N, Rosendahl E. The High-Intensity Functional Exercise (HIFE) Program. Department of Community Medicine and Rehabilitation, Umeå University; 2018. Available at: https://www. hifeprogram.se/en. Accessed December 15, 2019.

23. Hasselgren Nyberg L, Omgren M, Nyberg L, Gustavsson Y. The Swedish version of Physiotherapy Clinical Outcome Variable Scale. Nordisk Fysioterapi 1997;1:109-13.

24. Folstein MF, Folstein SE, McHugh PR. "Mini-mental state". A practical method for grading the cognitive state of patients for the clinician. J Psychiatr Res 1975;12:189-98.

25. Sheikh J, Yesavage J. Geriatric Depression Scale (GDS): Recent evidence and development of a shorter version. Clin Gerontol 1986;5: $165-73$.

26. Berggren D, Gustafson Y, Eriksson B, et al. Postoperative confusion after anesthesia in elderly patients with femoral neck fractures. Anesth Analg 1987;66:497-504.

27. Mahoney FI, Barthel DW. Functional evaluation: the Barthel Index. Md State Med J 1965;14:61-5.
28. Wade DT. Measurement in neurological rehabilitation. Oxford, England: Oxford University Press; 1992.

29. Sonn U, Törnquist K, Svensson E. The ADL taxonomy- from individual categorical data to ordinal categorical data. Scand J Occup Ther 1999;6:11-20.

30. Katz S, Akpom CA. A measure of primary sociobiological functions. Int J Health Serv 1976;6:493-507.

31. World Health Organization. Dementia: a public health priority. Available at: http://www.who.int/mental_health/publications/ dementia_report_2012. Accessed November 28, 2018.

32. Nordström P, Michaelsson K, Hommel A, Norrman PO, Thorngren KG, Nordström A. Geriatric rehabilitation and discharge location after hip fracture in relation to the risks of death and readmission. J Am Med Dir Assoc 2016;17:91e91-7.

33. Nordström P, Gustafson Y, Michaelsson K, Nordström A. Length of hospital stay after hip fracture and short term risk of death after discharge: a total cohort study in Sweden. BMJ 2015;350:h696.

34. Littbrand H, Stenvall M, Rosendahl E. Applicability and effects of physical exercise on physical and cognitive functions and activities of daily living among people with dementia: a systematic review. Am J Phys Med Rehabil 2011;90:495-518.

35. Magaziner J, Zimmerman SI, Gruber-Baldini AL, Hebel JR, Fox KM. Proxy reporting in five areas of functional status. Comparison with self-reports and observations of performance. Am J Epidemiol 1997; 146:418-28.

36. Hartigan I. A comparative review of the Katz ADL and the Barthel Index in assessing the activities of daily living of older people. Int J Older People Nurs 2007;2:204-12. 